\title{
Detection of seismic events triggered by $P$-waves from the 2011 Tohoku-Oki earthquake
}

\author{
Masatoshi Miyazawa ${ }^{1,2}$ \\ ${ }^{1}$ Disaster Prevention Research Institute, Kyoto University, Kyoto, Japan \\ ${ }^{2}$ Earthquake Research Institute, University of Tokyo, Tokyo, Japan
}

(Received December 27, 2011; Revised June 15, 2012; Accepted July 9, 2012; Online published January 28, 2013)

\begin{abstract}
Large-amplitude surface waves from the 2011 Tohoku-Oki earthquake triggered many seismic events across Japan, while the smaller amplitude $P$-wave triggering remains unclear. A spectral method was used to detect seismic events triggered by the first arriving $P$-waves over Japan. This method uses a reference event to correct for source and propagation effects, so that the local response near the station can be examined in detail. $P$-wave triggering was found in the regions where triggered non-volcanic tremor (NVT) has been observed, and some seismic and volcanic regions. The triggering strain due to $P$-waves is of the order of $10^{-8}$ to $10^{-7}$, which is 1 to 2 orders of magnitude smaller than the triggering strain necessary for the surface wave triggering. In the regions of NVT, the triggered event was not identified with slow events, but with other seismic events such as tectonic earthquakes. The sequence of triggering in the regions started with $P$-wave arrivals. The subsequent surface waves contributed to triggering of NVT, possibly together with slow slip, which resulted in the large amplitude of the NVT.
\end{abstract}

Key words: Tohoku-Oki earthquake, $P$-wave triggering, non-volcanic tremor.

\section{Introduction}

The 2011 Tohoku-Oki earthquake $\left(M_{\mathrm{w}}=9.0\right)$ triggered seismicity across Japan through static and quasi-static stress changes (Hirose et al., 2011; Ishibe et al., 2011; Okada et al., 2011; Toda et al., 2011) and dynamic stress changes generated by passing surface waves (Miyazawa, 2011; Yukutake et al., 2011). Though the initial arrival of body waves can result in abrupt stress changes, few reports have examined first arriving $P$-wave triggering for other large earthquakes (e.g., Miyazawa et al., 2005; Fischer et al., 2008a, b) because $P$-wave arrivals cause high-frequency transient stress changes and it is difficult to identify a local event using a high-pass filtering technique, particularly if the embedded event is minor. In the case of the 2011 Tohoku-Oki earthquake, the stress changes due to $P$-waves were more than one order of magnitude smaller than those from the triggering surface waves, however the investigation of $P$-wave triggering by the Tohoku-Oki earthquake can constrain mechanisms describing the onset of triggering.

This study also focuses on the possibility of triggering non-volcanic tremor (NVT) by $P$-waves. Since the discovery of NVT, or low-frequency tremor, in subduction zones (Obara, 2002; Rogers and Dragert, 2003) and along deep faults (Ohmi and Obara, 2002; Nadeau and Dolenc, 2005), the similarity to slow slip events is becoming recognized (Ide et al., 2007a, b); however, the mechanism of NVT oc-

Copyright (C) The Society of Geomagnetism and Earth, Planetary and Space Sciences (SGEPSS); The Seismological Society of Japan; The Volcanological Society of Japan; The Geodetic Society of Japan; The Japanese Society for Planetary Sciences; TERRAPUB.

doi:10.5047/eps.2012.07.003 currence remains unclear. The dynamic triggering of NVT by teleseismic waves provides a clue to understanding its mechanism because it is possible to directly investigate the stress/strain changes that excite NVT by distinguishing between incoming seismic waves and triggered events. Dynamic triggering of NVT associated with the passage of surface waves has been reported in the Nankai subduction zone (Obara, 2003; Miyazawa and Mori, 2005, 2006; Miyazawa and Brodsky, 2008; Miyazawa et al., 2008), the Cascadia subduction zone (Rubinstein et al., 2007, 2009), the Taiwan (Peng and Chao, 2008), the Hikurangi subduction zone (Fry et al., 2011), and at depth within the San Andreas Fault zone (Ghosh et al., 2009). Ghosh et al. (2009) also report NVT triggered by teleseismic $P$-waves. The amplitudes of triggered NVT are larger than those of typical NVT observed in the region (e.g., Obara, 2002; Miyazawa and Mori, 2006).

The 2011 Tohoku-Oki earthquake triggered NVT near the seismic-aseismic transition in the Nankai subduction zone in southwest Japan (Miyazawa, 2011), coincident with incoming large surface waves, as described for previous events (Miyazawa and Mori, 2006; Miyazawa and Brodsky, 2008; Miyazawa et al., 2008). Triggered NVT is easily identified from seismograms filtered with a pass-band of 4 $32 \mathrm{~Hz}$ (Figs. 1 and 2 and Appendix A). Significant NVT in western Shikoku is triggered mainly by surface waves that cause changes in the dynamic Coulomb failure function. Love waves that oscillate in the direction of relative plate motion on the subducting plate interface and/or Rayleigh waves that reduce normal stress on the plate interface are responsible for generating NVT. This observation supports the premise that the source mechanisms of triggered NVT are likely a result of shear fracture associ- 


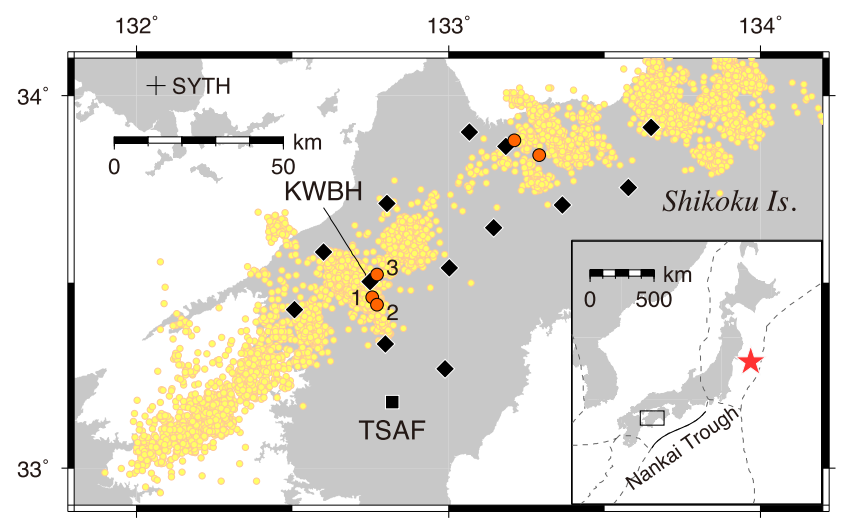

Fig. 1. Distribution of triggered non-volcanic tremor (NVT) and deep low-frequency (DLF) earthquakes in western Shikoku. Red circles indicate the epicenters of triggered NVT (Miyazawa, 2011) and the numbers correspond to the observed tremor in Fig. 2. Yellow circles indicate the epicenters of DLF earthquakes determined by the Japan Meteorological Agency (JMA). Diamonds and the square indicate Hi-net borehole stations used to locate triggered NVT and a broadband station, respectively. The hypocenter of the Tohoku-Oki earthquake is indicated by a red star in the inset map.

ated with plate subduction (Miyazawa and Brodsky, 2008; Miyazawa et al., 2008). It has been reported that among bursts of NVT dynamically triggered by surface waves at southwest Japan, large amplitude ones were triggered rather by Rayleigh waves, which involve a change in dilatational stress; thus, fluid released by dehydration of the subducting slab is thought to play an important role in the excitation of NVT (Miyazawa and Mori, 2006; Miyazawa and Brodsky, 2008; Miyazawa et al., 2008). Similarly to the triggering by dilatational stress changes associated with the passing of Rayleigh waves, compressional $P$-waves also have the potential to trigger NVT.

\section{Application of the Reference Spectrum Method to Detecting $P$-Wave Triggering}

\subsection{Spectral ratios}

The reference spectrum method is used to detect triggered events during the arrival of $P$-waves, where both the $P$-waves and triggered events are in the high-frequency range. This is accomplished by considering the difference in spectral content compared with a reference event, which, in this case, is a $M_{\mathrm{w}}=6.1$ earthquake that occurred in the off Tohoku region on March 9 (UT) (Table 1), 35.5 hours before the Tohoku-Oki mainshock, during a sequence of foreshocks that started on March 9, at 2:45 UT. The mechanism and hypocenter of the reference event are similar to those of the mainshock (Fig. 3). Since the reference event is much smaller than the mainshock while $P$-waves are clearly observed at all the stations over the main Japanese Islands, remote triggering during $P$-wave arrival is not expected.

The spectral ratio of the mainshock to the reference event can ideally reveal the ratio of the source spectra of the two events, which should be constant at any station. Spatial perturbations from the constant value reflect the local effects of wave propagation, including local triggered events. In the present case, the initial part of the mainshock is similar to

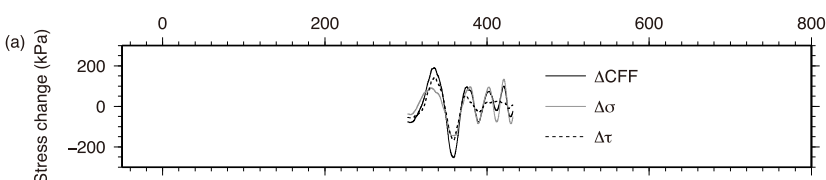

(b)


(d)

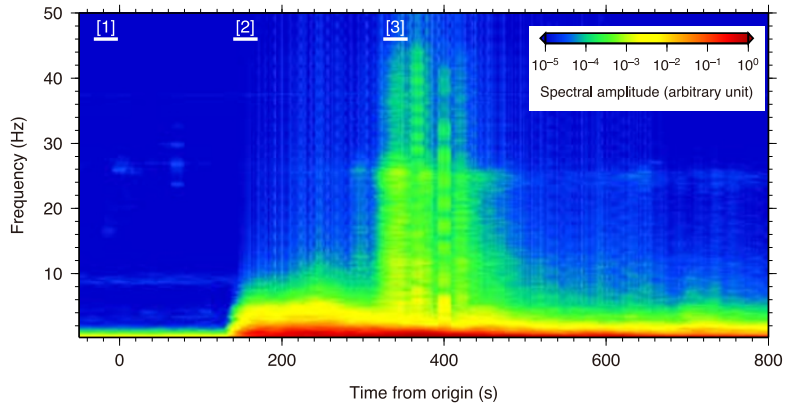

Fig. 2. The 2011 Tohoku-Oki earthquake recorded in western Shikoku. (a) Stress changes resolved for a mechanism of NVT at a depth of $30 \mathrm{~km}$ beneath the broadband station TSAF. $\Delta \sigma$ represents the normal stress change, $\Delta \tau$ is the shear stress change in the slip direction, and $\Delta \mathrm{CFF}$ is the Coulomb failure function change for the shear slip on the plate interface. (b) Root-mean-square envelope of the horizontal waveforms (4-32 $\mathrm{Hz}$ ) recorded at the borehole station $\mathrm{KWBH}$, showing the triggering of NVT during the arrival of surface waves. (c) Three traces $(0.01-1 \mathrm{~Hz})$, representing the vertical, radial, and transverse components, recorded at station TSAF. (d) Running spectra of the Tohoku-Oki earthquake with time windows of $20 \mathrm{~s}$ for KWBH. White lateral bars show time windows used in Fig. 4. Station locations are shown in Fig. 1.

the reference event, whereas the later part is quite different (Ide et al., 2011). Consequently, this analysis focuses on the first $25 \mathrm{~s}$ after the onset of $P$-waves and before the arrival of $S$-waves, in order to optimize the trade-off between a longer time window required to observe strong triggering by large $P$-waves, and a shorter time window which enables examination over a broader area before the arrival of subsequent $S$-waves. The spectral ratio is calculated after removing each background noise spectrum, which is also obtained for a $25 \mathrm{~s}$ time window before the origin for each station. The spectral ratio for a given frequency $f$ is given by

$$
R(f)=\frac{A_{\mathrm{p}}-A_{\mathrm{bg}}}{A_{\mathrm{p}}^{\mathrm{ref}}-A_{\mathrm{bg}}^{\mathrm{ref}}}
$$

where $A$ is the root-mean-square spectral amplitude of three-component spectra for $f$, the superscript "ref" denotes the reference event, and "P" and "bg" represent $P$ wave and background, respectively. The spectral ratio is averaged between 0.5 and $2 \mathrm{~Hz}$, which includes the dominant frequency of NVT. An example of Fourier spectra at 
Table 1. Reference events and the Tohoku-Oki earthquake.

\begin{tabular}{|c|c|c|c|c|c|c|c|}
\hline & $\begin{array}{l}\text { Centro } \\
\text { [Origir }\end{array}$ & $\begin{array}{l}\text { ime (UT) } \\
\text { me (UT)] }\end{array}$ & $\begin{array}{c}\text { Lat } \\
(\mathrm{deg})\end{array}$ & $\begin{array}{c}\text { Lon } \\
\text { (deg) }\end{array}$ & $\begin{array}{c}\text { Depth } \\
(\mathrm{km})\end{array}$ & $M_{\mathrm{w}}$ & Catalogue \\
\hline \multirow[t]{3}{*}{ Reference Events } & $2011 / 3 / 9$ & $18: 16: 18.9$ & 38.33 & 142.80 & 28.6 & 6.1 & Global CMT \\
\hline & $2011 / 3 / 9$ & $21: 22: 19.6$ & 38.29 & 142.91 & 22.5 & 6.0 & Global CMT \\
\hline & $2011 / 3 / 9$ & 21:24:09.0 & 38.27 & 142.82 & 22.6 & 6.5 & Global CMT \\
\hline \multirow[t]{2}{*}{ Tohoku-Oki Earthquake } & $2011 / 3 / 11$ & $5: 47: 32.8$ & 37.52 & 143.05 & 20.0 & 9.1 & Global CMT \\
\hline & & [5:46:18.12] & 38.104 & 142.861 & 23.7 & 9.0 & JMA \\
\hline
\end{tabular}

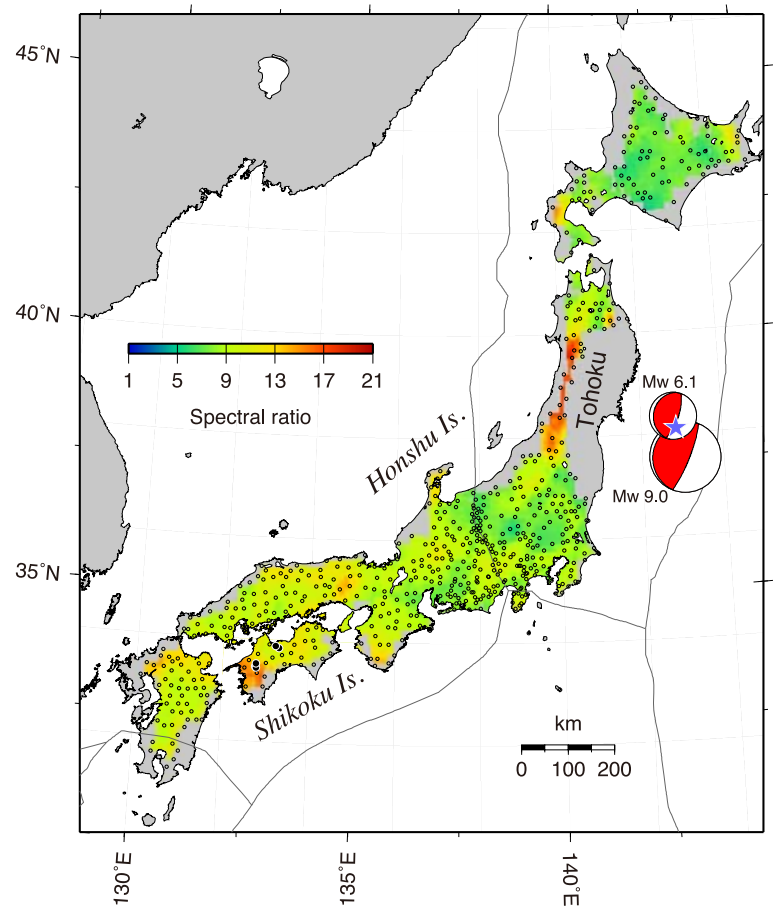

Fig. 3. $\quad P$-wave spectral ratios of the $M_{\mathrm{w}} 9.0$ Tohoku-Oki earthquake compared with the $M_{\mathrm{w}} 6.1$ reference earthquake over the main Japanese Islands. The spectral ratio is averaged between 0.5 and $2 \mathrm{~Hz}$. Also shown are the Centroid Moment Tensor (CMT) solutions of the two earthquakes (Nettles et al., 2011). The star represents the hypocenter of the Tohoku-Oki earthquake, from the JMA catalogue. The filled circles indicate the epicenters of triggered NVT. $638 \mathrm{Hi}$-net stations used are shown by open circles.

the station KWBH in western Shikoku is shown in Fig. 4.

Figure 3 shows the spectral ratios at $638 \mathrm{Hi}$-net borehole stations, where the spectral ratios with poor signal-to-noise for the reference event (i.e. $A_{\mathrm{p}}^{\mathrm{ref}} / A_{\mathrm{bg}}^{\mathrm{ref}}<15$ ) are excluded. Two regions with high values are found in Tohoku and western Shikoku. The values in Tohoku are due mainly to the directivity effect of the fault rupture (Ide et al., 2011), which is not observed for the reference earthquake. The high value in western Shikoku is observed at multiple stations and interpreted to represent a region of NVT activity.

There is also a region of high spectral ratio around $\left(135^{\circ} \mathrm{E}, 35^{\circ} \mathrm{N}\right)$ in Honshu, coincident with the location of the Yamasaki Fault. However, there is no evidence of a triggered event in this region, even during and after the passage of surface waves. Furthermore, there are some moderately high spectral ratios along the coast. In the next section, the statistically significant observations in this spectral ratio map will be shown through a non-parametric statistical test.

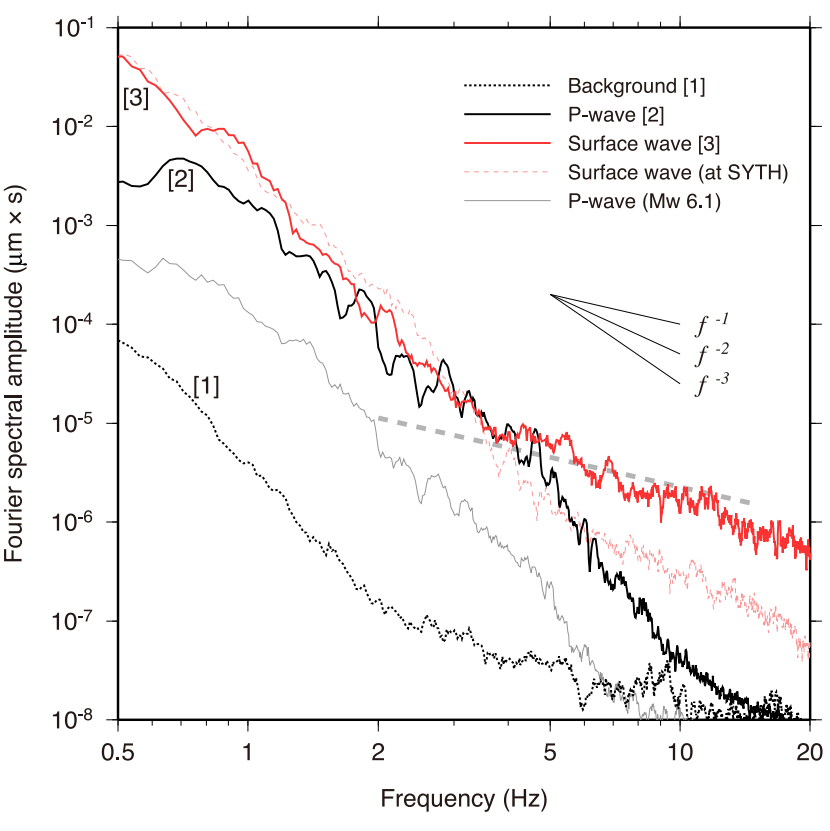

Fig. 4. Fourier spectra of horizontal components of the 2011 Tohoku-Oki earthquake. The spectra of the background, $P$-waves, and surface waves that include triggered NVT, are obtained using the time windows 1 , 2, and 3 at KWBH shown in Fig. 2(d). Also shown are the surface wave spectrum for the same time window at SYTH and the spectrum of $P$-waves at KWBH from the $M_{\mathrm{w}} 6.1$ reference earthquake. The station SYTH is shown by a cross in Fig. 1.

These perturbations are small so that the simple approaches that compare spectral amplitudes at different stations or that look at temporal variations in the running spectra cannot detect the local signals. For example, Fig. 2(d) shows the running spectra at $\mathrm{KWBH}$, where relatively high spectral ratio values are observed. Triggering of NVT by surface waves is clearly seen, while the embedded signals during $P$-wave arrivals are unclear.

The higher frequency ranges up to $\sim 10 \mathrm{~Hz}$ are excluded from the map of the spectral ratios. Figure 5 shows the spectral ratios for the higher-frequency ranges of $2-4 \mathrm{~Hz}$, 4-8 Hz, and 8-16 Hz. The perturbations define a pattern similar to Fig. 3, however the higher the frequency range becomes, the poorer the signal-to-noise ratio becomes at some distance from the hypocenter.

\subsection{Non-parametric statistical test}

To statistically evaluate if the high spectral ratios observed in Fig. 3 are due to actual event signals or incidental perturbations, the Kolmogorov-Smirnov (K-S) two-sample test is performed. The $\mathrm{K}-\mathrm{S}$ test is a non-parametric statistical test, which does not rely on any particular distribution 
(a)

(c)
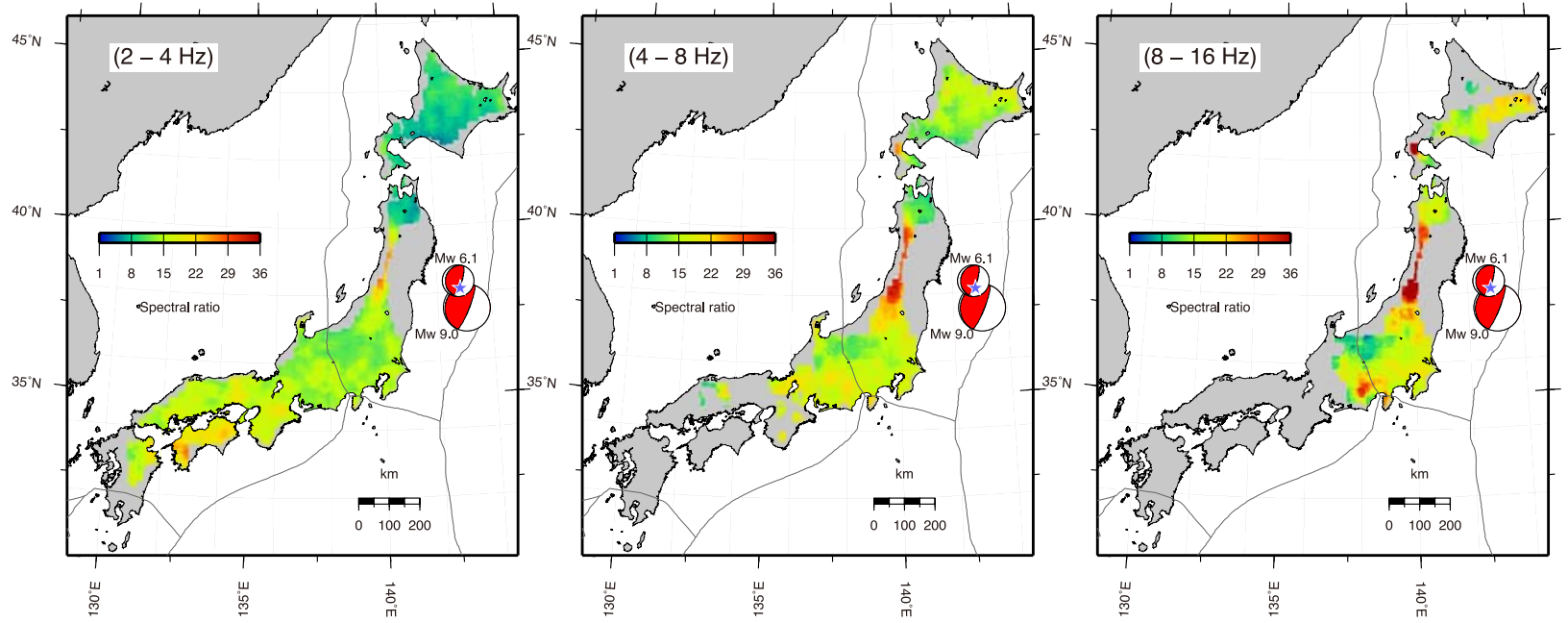

Fig. 5. $P$-wave spectral ratios of the $M_{\mathrm{w}} 9.0$ Tohoku-Oki earthquake compared with the $M_{\mathrm{w}} 6.1$ reference earthquake over the main Japanese Islands. The spectral ratios are averaged between (a) 2 and $4 \mathrm{~Hz}$, (b) 4 and $8 \mathrm{~Hz}$, and (c) 8 and $16 \mathrm{~Hz}$.

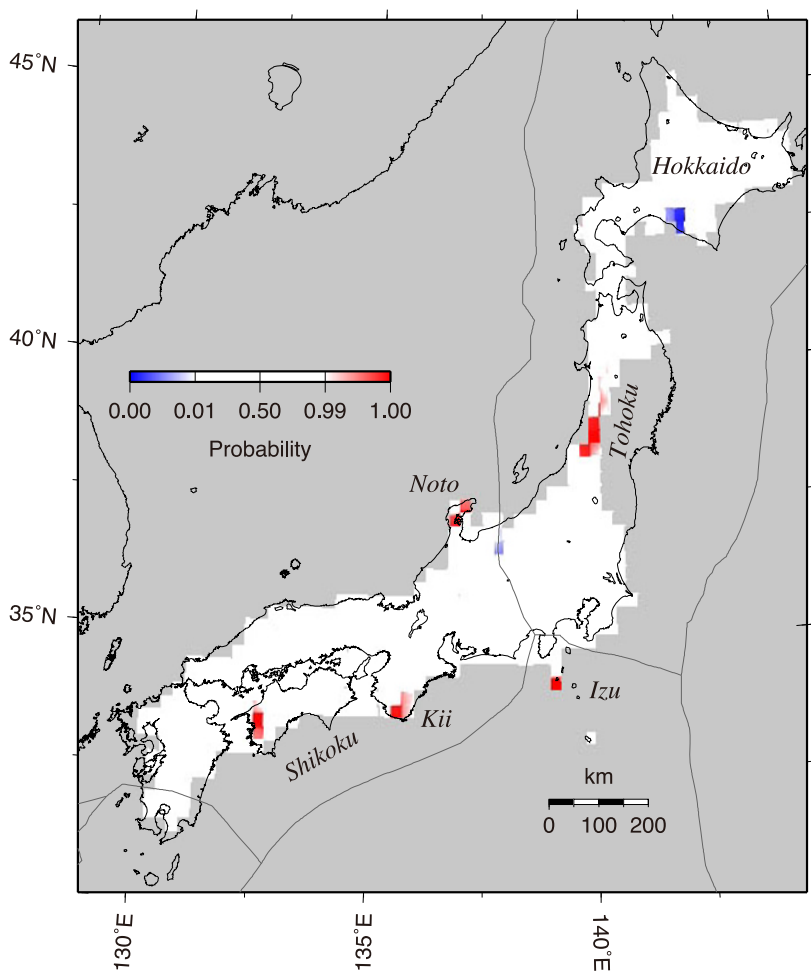

Fig. 6. The Kolmogorov-Smirnov two-sample test showing the two-sided probability of exceeding the difference of two samples calculated under the null hypothesis of equal distributions. Two samples refer to the spectral ratios in a local specific region and a large region. The probability is substituted for its complementary probability if the difference between the empirical cumulative distribution function of the local sample minus that of the regional sample is positive. The high probabilities in red show regions for which the spectral ratios are significantly large and the low probabilities in blue show regions for which the spectral ratios are significantly small.

of values. A local sample that refers to values at adjacent stations within $0.5 \mathrm{deg} \times 0.5 \mathrm{deg}$ in a specific region, which corresponds to less than 10 stations, is compared with another large regional sample that refers to values at more than 200 stations including the local sample. The two-sided probability of exceeding the difference of two samples, $p$, is calculated under the null hypothesis of equal distributions. Figure 6 shows the probability, where the value is the complementary probability, $1-p$, if the difference between the empirical cumulative distribution function of the small local sample minus that of the large regional sample is positive. The regions with statistically significantly large and small values are in red and blue, respectively. In the region of high spectral ratios in western Shikoku where 6 adjacent stations are chosen as the local sample, the probability is about $99.93 \%$, which can reject the null hypothesis with a confidence of $99 \%$. Hence the high spectral ratio in western Shikoku is considered to be statistically significant. On the other hand, the probability at the Yamazaki Fault region is about $86 \%$, which fails to reject the null hypothesis, with the possibility that values in this region may be incidentally high.

There are other regions with statistically significant values found in southern Hokkaido, Izu island, Noto peninsula, and Kii peninsula. In southern Hokkaido, the spectral ratios are significantly small, which is different from other regions. Hokkaido is located close to the null-axis directions of source mechanisms of the Tohoku-Oki and the reference earthquakes (Fig. 3). Then, the spectral ratios are very sensitive to slight differences of the mechanisms, which causes the variation of the spectral ratios.

\subsection{Other reference events}

To confirm the results, it might be preferable to see the spectral ratios by using other reference events. As mentioned in the previous section, the magnitude of the reference event should be moderate and the mechanism and hypocenter of the reference event should be similar to those of the mainshock. There are two other candidate events in the off Tohoku region; $M_{\mathrm{w}}=6.0$ and $M_{\mathrm{w}}=6.5$ on March 9 (UT) during the sequence of foreshocks (Table 1). The spectral ratios using these reference events are shown in Fig. 7; however, both events produced poorer results compared to the $M_{\mathrm{w}} 6.1$ event used in the analysis described 
(a)



(b)

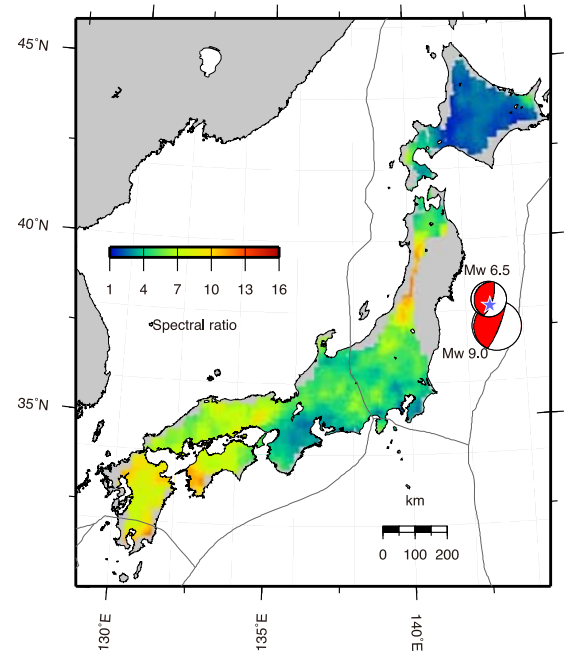

Fig. 7. $P$-wave spectral ratios of the $M_{\mathrm{w}} 9.0$ Tohoku-Oki earthquake compared with (a) the $M_{\mathrm{w}} 6.0$ reference earthquake and (b) the $M_{\mathrm{w}} 6.5$ reference earthquake over the main Japanese Islands. The spectral ratio is averaged between $0.5 \mathrm{and} 2 \mathrm{~Hz}$. The Centroid Moment Tensor (CMT) solutions of these earthquakes (Nettles et al., 2011) are shown.

above. In the case of the reference event of $M_{\mathrm{w}} 6.0$, the $P$-waves from the event were slightly too small to overwhelm the background noise level at some distance from the hypocenter. In the case of the other reference event of $M_{\mathrm{w}}$ 6.5 , the spectral ratios are generally similar to Fig. 3. Also the $M_{\mathrm{w}} 6.5$ event is used for the empirical Green's function method to estimate the source model of the Tohoku-Oki earthquake (Kurahashi and Irikura, 2011). However, the $M_{\mathrm{w}} 6.5$ event occurred about $110 \mathrm{~s}$ after the $M_{\mathrm{w}} 6.0$ event, so both the $P$-wave arrivals from the $M_{\mathrm{w}} 6.5$ event and $S$ and surface-wave arrivals from the previous $M_{\mathrm{w}} 6.0$ event are simultaneously observed at some stations. Moreover the values in Hokkaido are relatively small, which reflects the difference of the mechanisms of the reference event and the initial rupture of the mainshock. In the present study, only the $M_{\mathrm{w}} 6.1$ event can be used as a suitable reference event.

\section{Discussion and Conclusions}

The results indicate that $P$-waves from the Tohoku-Oki earthquake most likely triggered seismicity in Izu, the Noto peninsula, the Kii peninsula, and western Shikoku. In these regions, the dynamic strain changes by the initial $P$-waves are of the order of $10^{-8}$ to $10^{-7}$, while Miyazawa (2011) shows that values exceeding $10^{-6}$ seem to be necessary for the triggering of earthquakes by surface waves. This suggests that the events detected triggered by $P$-waves may not be usual earthquakes, but seismic events with other mechanisms such as volcanic source and fluid related fracture. Otherwise, there may be the possibility of an overestimation of the triggering threshold for tectonic earthquakes in the previous study.

The Izu islands are a volcanic area of previous high seismicity. Surface waves from the Tohoku-Oki earthquakes triggered volcanic seismicity (Miyazawa, 2011) in this region. However, $P$-wave triggering was observed at a single station. This observation possibly indicates that the seismicity triggered by $P$-waves is also related to the volcanic activity. Such $P$-wave triggering in geothermal and volcanic regions has been reported at Aso volcano, Japan (Miyazawa et al., 2005). On the other hand, in the Hida volcanic region, central Honshu, where the seismicity was previously high and the surface waves triggered earthquakes similarly to the Izu Islands (Miyazawa, 2011), no clear $P$-wave triggering was found in this study. In both regions, seismicity increased after the Tohoku-Oki earthquake (Hirose et al., 2011). This difference may be due to the initially stressed states, the magnitude of triggered events, and the source mechanisms of the seismic events in the regions.

In the Noto peninsula, the Noto earthquake $\left(M_{\mathrm{w}}=6.7\right)$ occurred in 2007 and was followed by aftershocks. Neither surface wave triggering of earthquakes, nor increased seismicity, was observed after the Tohoku-Oki earthquake. In the Kii peninsula, the high spectral values are close to the region of NVT activity, while the surface-wave triggering of NVT was not observed.

In western Shikoku, the high spectral values are interpreted to represent a region of NVT activity, partly because similar NVT in this region was triggered by the arrival of surface waves. Figure 4 shows the Fourier spectra of horizontal components at KWBH, for the background, $P$-waves, and surface waves that include triggered NVT. The time windows used to obtain the spectra are shown in Fig. 2(d). The spectrum of surface wave arrivals shows a roughly $1 / f$ frequency decay for the frequency range higher than $\sim 4 \mathrm{~Hz}$ as indicated by a straight broken line in Fig. 4. This corresponds to the observation of triggered NVT, because there is the difference between the surface wave spectra at KWBH and SYTH with a similar epicentral distance from the Tohoku-Oki earthquake, where triggered NVT was not observed at SYTH. This $1 / f$ decay is consistent with a scaling law for slow events (Ide et al., 2007a). If the perturbation of spectral ratios in western Shikoku indicates the observation of triggered NVT, a similar relationship should have been observed for the $P$-wave spectrum. It is assumed that $\sim+10 \%$ perturbations of the $0.5-2 \mathrm{~Hz}$ spectral ratios 
of initial $P$-waves in western Shikoku (Figs. 2 and 3), which correspond to a few $\mu \mathrm{m} / \mathrm{s}$ perturbations in the seismogram, are the amplitude of triggered slow events akin to NVT. The spectral amplitude of possible slow events around 1 $\mathrm{Hz}$ should be comparable to the value of the straight broken line in Fig. 4. However, the present $P$-wave spectrum is rather proportional to $\sim 1 / f^{3}$, which is observed for usual earthquakes and is not governed by the scaling law for slow events. These observations in western Shikoku suggest that $P$-waves triggered seismic events that are not identified as slow events in terms of the scaling law.

It is remarkable that $P$-wave triggering was found in regions where NVT has been observed triggered by the passage of surface waves. If the triggered event in western Shikoku is related to the NVT, $P$-wave triggering is the beginning of the triggering sequence of NVT. The triggering strain due to $P$-waves is of the order of $10^{-8}$, which is 2 orders of magnitude smaller than the triggering strain found for surface-wave triggering. Miyazawa and Brodsky (2008) observed clear surface-wave triggering when the normal strain changes are at least of the order of $10^{-8}$. In the present method, the epicenter of the triggered events is not well resolved and the depth is not determined, however, the region with a high spectral ratio in western Shikoku corresponds to the locations of triggered NVT during surfacewave arrivals.

In central Shikoku, NVT triggered by passing surface waves from the Tohoku-Oki earthquake has been observed (Fig. 1) (Miyazawa, 2011), however the results of the spectral ratios in this region do not show clear $P$-wave triggering as seen in western Shikoku. If the amplitudes of seismic events triggered by $P$-waves were smaller than a few $\mu \mathrm{m} / \mathrm{s}$, the triggering would not be detected using this approach.

It is suggested that the sequence of triggering in western Shikoku started with the $P$-wave arrival, which initially caused pressure changes. $P$-wave triggering was observed for only the first $25 \mathrm{~s}$ time window because of the limited time windows as described in Subsection 2.1; however, the subsequent arrival of larger $P$-waves also potentially triggered the seismic events. Considering that the high spectral ratios are observed at stations where triggered NVT has been clearly observed, it is speculated that the triggered events may be located near the plate-boundary and the region of NVT. Once the events have occurred, the state of stress in the surrounding rock becomes increasingly unstable, close to failure. Then the subsequent large stress changes due to surface waves effectively trigger NVT via Coulomb failure stress, producing NVT much larger than that of background NVT. The triggering by $P$ waves and Rayleigh waves (both volumetric perturbations) most likely indicate a contribution by fluids to the occurrence of the triggering sequence of NVT (Miyazawa and Brodsky, 2008). It is possible that remotely triggered slowslip (Itaba and Ando, 2011; Shelly et al., 2011) also causes large-amplitude NVT during surface-wave arrivals, because large-amplitude NVT has been observed to be triggered by slow slip events associated with earth tides (Nakata et al., 2008). The occurrence of triggering depends on the state in the region (Miyazawa and Mori, 2005), but the process can start from $P$-wave triggering followed by a possible slow slip or other mechanisms that may result in larger amplitude NVT triggered by subsequent surface waves.

Acknowledgments. I thank Zhigang Peng, Jim Mori and two anonymous reviewers for thoughtful comments. I used the JMA earthquake catalogue. Figures are produced using the Generic Mapping Tools (Wessel and Smith, 1998).

\section{Appendix A. Surface Wave Triggering of NVT}

NVT triggered by surface waves below western Shikoku is considered. Triggered NVT is divided into three parts based on the period of the surface wave and the locations of NVT are obtained using an envelope correlation method (Miyazawa and Mori, 2006; Miyazawa, 2011) (Fig. 1). The locations are within the source region of deep lowfrequency earthquakes identified in the Japan Meteorological Agency (JMA) catalogue. Continuous NVT consists of extended series of deep low-frequency earthquakes (Shelly et al., 2007). The depths of triggered NVT are $\sim 30 \mathrm{~km}$ or shallower. No triggering of NVT has been observed in other regions of NVT activity in western Japan.

Assuming that NVT is a slow-slip event on the plate boundary (Ide et al., 2007b), the following parameters were calculated using seismograms observed at the broadband seismic station TSAF (Miyazawa and Brodsky, 2008) (Figs. 1 and 2): the normal stress change $\Delta \sigma$, the shear stress change $\Delta \tau$, and the Coulomb failure function changes $\triangle \mathrm{CFF}$ with an apparent friction coefficient $\mu^{\prime}=0.6$, at a depth of $30 \mathrm{~km}$ due to the passage of surface waves. The dynamic Coulomb failure stress changes seem to correlate with the amplitude of triggered NVT. The first NVT was triggered mainly by Love waves and others were triggered mainly by Rayleigh waves.

Triggered NVT is easily identified from seismograms filtered with a pass-band of 4-32 Hz. In previous studies, the pass-band of $\sim 1$ to $\sim 10 \mathrm{~Hz}$ is used because the NVT has a predominant frequency in this range. In the present study, the epicentral distance to the triggering event is very small, and large signals of higher than a few $\mathrm{Hz}$ from the mainshock and its aftershocks are simultaneously observed during the arrival of surface waves. So a higher frequency band (4-32 Hz) is required to detect triggered NVT, although there should also be NVT signals around a few Hz (Fig. 4).

\section{References}

Fischer, A. D., Z. Peng, and C. G. Sammis, Dynamic triggering of high-frequency bursts by strong motions during the 2004 Parkfield earthquake sequence, Geophys. Res. Lett., 35, L12305, doi:10.1029/2008GL033905, 2008a.

Fischer, A. D., C. G. Sammis, Y. Chen, and T.-L. Teng, Dynamic triggering by strong-motion $\mathrm{P}$ and $\mathrm{S}$ waves: Evidence from the 1999 Chi-Chi, Taiwan, earthquake, Bull. Seismol. Soc. Am., 98, 580-592, doi:10.1785/0120070155, 2008b.

Fry, B., K. Chao, S. Bannister, Z. Peng, and L. Wallace, Deep tremor in New Zealand triggered by the 2010 Mw8.8 Chile earthquake, Geophys. Res. Lett., 38, L15306, doi:10.1029/2011GL048319, 2011.

Ghosh, A., J. E. Vidale, Z. Peng, K. C. Creager, and H. Houston, Complex nonvolcanic tremor near Parkfield, California, triggered by the great 2004 Sumatra earthquake, J. Geophys. Res., 114, B00A15, doi:10.1029/2008JB006062, 2009.

Hirose, F., K. Miyaoka, N. Hayashimoto, T. Yamazaki, and M. Nakamura, Outline of the 2011 off the Pacific coast of Tohoku Earthquake $\left(M_{\mathrm{w}}\right.$ 9.0)-Seismicity: foreshocks, mainshock, aftershocks, and induced activity-, Earth Planets Space, 63, 513-518, doi:10.5047/eps.2011.05.019, 2011. 
Ide, S., G. C. Beroza, D. R. Shelly, and T. Uchide, A scaling law for slow earthquakes, Nature, 447, 76-79, doi:10.1038/nature05780, 2007a.

Ide, S., D. R. Shelly, and G. C. Beroza, Mechanism of deep low frequency earthquakes: Further evidence that deep non-volcanic tremor is generated by shear slip on the plate interface, Geophys. Res. Lett., 34, L03308, doi:10.1029/2006GL028890, 2007b.

Ide, S., A. Baltay, and G. C. Beroza, Shallow dynamic overshoot and energetic deep rupture in the $2011 \mathrm{Mw} 9.0$ Tohoku-Oki earthquake, Science, 332, 1426-1429, doi:10.1126/science.1207020, 2011.

Ishibe, T., K. Shimazaki, K. Satake, and H. Tsuruoka, Change in seismicity beneath the Tokyo metropolitan area due to the 2011 off the Pacific coast of Tohoku Earthquake, Earth Planets Space, 63, 731-735, doi:10.5047/eps.2011.06.001, 2011.

Itaba, S. and R. Ando, A slow slip event triggered by teleseismic surface waves, Geophys. Res. Lett., 38, L21306, doi:10.1029/2011GL049593, 2011.

Kurahashi, S. and K. Irikura, Source model for generating strong ground motions during the 2011 off the Pacific coast of Tohoku Earthquake, Earth Planets Space, 63, 571-576, doi:10.5047/eps.2011.06.044, 2011.

Miyazawa, M., Propagation of an earthquake triggering front from the 2011 Tohoku-Oki earthquake, Geophys. Res. Lett., 38, L23307, doi:10.1029/2011GL049795, 2011.

Miyazawa, M. and E. E. Brodsky, Deep low-frequency tremor that correlates with passing surface waves, J. Geophys. Res., 113, B01307, doi:10.1029/2006JB004890, 2008.

Miyazawa, M. and J. Mori, Detection of triggered deep low-frequency events from the 2003 Tokachi-oki earthquake, Geophys. Res. Lett., 32, L10307, doi:10.1029/2005GL022539, 2005.

Miyazawa, M. and J. Mori, Evidence suggesting fluid flow beneath Japan due to periodic seismic triggering from the 2004 Sumatra-Andaman earthquake, Geophys. Res. Lett., 33, L05303, doi:10.1029/2005GL025087, 2006.

Miyazawa, M., I. Nakanishi, Y. Sudo, and T. Ohkura, Dynamic response of frequent tremors at Aso volcano to teleseismic waves from the 1999 Chi-Chi, Taiwan earthquake, J. Volcanol. Geotherm. Res., 147, 173186, doi:10.1016/j.jvolgeores.2005.03.012, 2005.

Miyazawa, M., E. E. Brodsky, and J. Mori, Learning from dynamic triggering of low-frequency tremor in subduction zones, Earth Planets Space, 60, e17-e20, 2008.

Nadeau, R. M. and D. Dolenc, Nonvolcanic tremors deep beneath the San Andreas Fault, Science, 307, 389, doi:10.1126/science.1107142, 2005.

Nakata, R., N. Suda, and H. Tsuruoka, Non-volcanic tremor resulting from the combined effect of Earth tides and slow slip events, Nat. Geosci., 1, 676-678, doi:10.1038/ngeo288, 2008.

Nettles, M., G. Ekström, and H. C. Koss, Centroid-moment-tensor analysis of the 2011 off the Pacific coast of Tohoku Earthquake and its larger foreshocks and aftershocks, Earth Planets Space, 63, 519-523, doi:10.5047/eps.2011.06.009, 2011.
Obara, K., Nonvolcanic deep tremor associated with subduction in southwest Japan, Science, 296, 1679-1680, doi:10.1126/science.1070378, 2002.

Obara, K., Time sequence deep low-frequency tremors in the southwest japan subduction zone: Triggering phenomena and periodic activity, $J$. Geogr., 112, 837-849, 2003.

Ohmi, S. and K. Obara, Deep low-frequency earthquakes beneath the focal region of the Mw 6.7 2000 Western Tottori earthquake, Geophys. Res. Lett., 29, 1807, doi:10.1029/2001GL014469, 2002.

Okada, T., K. Yoshida, S. Ueki, J. Nakajima, N. Uchida, T. Matsuzawa, N. Umino, A. Hasegawa, and Group for the aftershock observations of the 2011 off the Pacific coast of Tohoku Earthquake, Shallow inland earthquakes in NE Japan possibly triggered by the 2011 off the Pacific coast of Tohoku Earthquake, Earth Planets Space, 63, 749-754, doi:10.5047/eps.2011.06.027, 2011.

Peng, Z. and K. Chao, Non-volcanic tremor beneath the Central Range in Taiwan triggered by the $2001 \mathrm{Mw} 7.8$ Kunlun earthquake, Geophys. $J$. Int., 175, 825-829, doi:10.1111/j.1365-246X.2008.03886.x, 2008.

Rogers, G. and H. Dragert, Episodic tremor and slip on the Cascadia subduction zone: The chatter of silent slip, Science, 300, 1942-1943, doi:10.1126/science.1084783, 2003.

Rubinstein, J. L., J. E. Vidale, J. Gomberg, P. Bodin, K. C. Creager, and S. D. Malone, Non-volcanic tremor driven by large transient shear stresses, Nature, 448, 579-582, doi:10.1038/nature06017, 2007.

Rubinstein, J. L., J. Gomberg, J. E. Vidale, A. G. Wech, H. Kao, K. C. Creager, and G. Rogers, Seismic wave triggering of nonvolcanic tremor, episodic tremor and slip, and earthquakes on Vancouver Island, J. Geophys. Res., 114, B00A01, doi:10.1029/2008JB005875, 2009.

Shelly, D. R., G. C. Beroza, and S. Ide, Non-volcanic tremor and low-frequency earthquake swarms, Nature, 446, 305-307, doi:10.1038/nature05666, 2007.

Shelly, D. R., Z. Peng, D. P. Hill, and C. Aiken, Triggered creep as a possible mechanism for delayed dynamic triggering of tremor and earthquakes, Nat. Geosci., 4, 384-388, doi:10.1038/ngeo1141, 2011.

Toda, S., J. Lin, and R. S. Stein, Using the $2011 M_{\mathrm{w}} 9.0$ off the Pacific coast of Tohoku Earthquake to test the Coulomb stress triggering hypothesis and to calculate faults brought closer to failure, Earth Planets Space, 63, 725-730, doi:10.5047/eps.2011.05.010, 2011.

Wessel, P. and W. H. F. Smith, New, improved version of generic mapping tools released, Eos Trans. AGU, 79(47), 579, doi:10.1029/98EO00426, 1998.

Yukutake, Y., R. Honda, M. Harada, T. Aketagawa, H. Ito, and A. Yoshida, Remotely-triggered seismicity in the Hakone volcano following the 2011 off the Pacific coast of Tohoku Earthquake, Earth Planets Space, 63, 737-740, doi:10.5047/eps.2011.05.004, 2011.

M. Miyazawa (e-mail: miyazawa@rcep.dpri.kyoto-u.ac.jp) 